\title{
Discurso intolerante y esfera pública
}

Intolerant discourse and the public sphere

Rafael Alcácer Guirao, Universidad Rey Juan Carlos - rafael.alcacer@urjc.es

\section{Resumen}

La diversidad cultural e ideológica inherente a las sociedades actuales es foco potencial de conflictos. En el seno de dichos conflictos se instala el discurso de odio y su restricción por el Derecho penal, surgiendo la cuestión de si debe restringirse la deliberación democrática en el ámbito de la esfera pública en aras a proteger como vehículo para fomentar el discurso de las minorías.

\section{Palabras clave}

Discurso de odio, libertad de expresión, democracia intolerancia, esfera pública

\section{Abstract}

Cultural and political diversity inherent in today's societies is a potential focus of conflicts. At the center of such conflicts lies the hate speech controversy and its restriction by the criminal law, emerging the question about the legitimacy of democratic deliberation restriction in order to protect as a vehicle to encourage the speech of those minorities.

\section{Keywords}

Hate speech, freedom of expression, democracy, intolerance, public sphere

\section{Sumario}

1. ¿Cuánta tolerancia a los intolerantes? 2. El daño del discurso del odio. 3. El "efecto silenciador" como daño a la reputación comunicativa. 4. ¿Restringir la libertad de expresión para proteger la libertad de expresión? 5. El ámbito de la opinión pública. 6. Entre espontaneidad y regulación. 7. Regulación en la esfera pública: formas de intolerancia frente al discurso intolerante. 


\section{1. ¿Cuánta tolerancia a los intolerantes?}

El conflicto social que suscita el discurso de odio puede formularse con el siguiente interrogante: ¿cuánta intolerancia debe concederse a los intolerantes? La estabilidad en sociedades pluralistas y complejas presupone alcanzar un acuerdo sobre las normas de convivencia que pueda surgir de las distintas doctrinas morales o religiosas que cada cual profesa -lo que Rawls denomina el consenso entrecruzado (Rawls, 2004: 165)-. La deliberación racional, consustancial sistema democrático, presupone, en consecuencia, que cada ciudadano pueda exponer a otros su concepción sobre los asuntos públicos, y la expectativa recíproca de que éstos se mostrarán dispuestos a comprender el sentido y argumentos en que tal concepción se sostiene. Pero dado que los planteamientos políticos emanarán inevitablemente de cada particular conjunto de creencias morales 0 religiosas, la deliberación pública en sociedades pluralistas exigirá también un cierto grado de compromiso en asimilar y tolerar esas doctrinas comprehensivas (McKinnon, 2006: 62). La tolerancia destaca, así, como una de las virtudes políticas inherentes a la ciudadanía democrática, pues constituye un presupuesto necesario para intervenir en la deliberación pública racional en sociedades pluralistas (Rawls, 2004: 89 ss.). Como se ha afirmado, "tolerar y ser tolerado...es la ocupación de los ciudadanos en una democracia" (Walzer, 1997: xi).

Pero esa tolerancia, entendida como respeto mutuo entre iguales y como disposición al entendimiento, no puede imponerse por la coacción estatal, sino que habría de surgir espontáneamente del propio uso de la razón pública entre visiones comprehensivas y enfrentadas de lo bueno, de la convivencia dialéctica entre distintas comunidades culturales (Forst, 2008: 73). El Estado podrá, todo lo más, regular el entorno en el que tiene lugar el debate público, y fomentar el acercamiento entre tradiciones o culturas, mas no incurrir en el contrasentido de imponer la tolerancia por medios coactivos. Así las cosas, entre las condiciones necesarias para el desarrollo de la tolerancia individual, para fomentar una ciudadanía permeable al discurso del otro, está la propia tolerancia estatal hacia esos discursos, hacia la propagación de las opiniones minoritarias e incluso disidentes.

Conceptualmente, la tolerancia presupone un conjunto de razones de rechazo a determinada práctica social (o, en nuestro caso, determinado discurso), y un conjunto de razones de aceptación -pragmáticas, éticas o morales- que en la ponderación con las primeras ostentarán mayor peso; ponderación que dependerá del contexto en que se despliegue la relación entre los sujetos activo y pasivo de la tolerancia. Dada su dependencia normativa, "la tolerancia puede estar basada en el respeto mutuo, o puede en cambio ser manifestación de rechazo o dominación" (Forst, 2012: 50 ss.). Ello dependerá en gran medida de cuáles sean esas razones de aceptación, estando la tolerancia más o menos arraigada según emane de criterios éticos o de justicia o derive de motivos puramente pragmáticos. Desde esa tensión entre rechazo y aceptación inherente a la tolerancia, podríamos establecer cinco niveles graduales de tratamiento a aquellos discursos sociales prima facie rechazables por un Estado democrático, que pueden entenderse también como alternativas político-criminales para lidiar socialmente con los discursos y prácticas intolerantes (McKinnon, 2008: $56 \mathrm{ss}$.$) :$

Represión punitiva. Ciertamente, no puede aquí hablarse de tolerancia en grado alguno, pues no entran en juego razones de aceptación. Como nítido ejemplo de esta opción frente a tradiciones culturales minoritarias puede citarse, entre otros, la prohibición de la mutilación genital femenina. Y es también la opción adoptada con carácter general frente al discurso de odio (véase el artículo 510 del Código Penal).

Disuasión no coactiva. Sin llegar a la represión, el Estado puede también ejercer la intolerancia adoptando políticas dirigidas a desalentar o silenciar aquellos discursos o prácticas que considera rechazables, regulando administrativamente los cauces de manifestación de esa práctica o discurso, 0 articulando políticas activas dirigidas a disminuir o silenciar su difusión -excluyéndolas de la concesión de ayudas o subvenciones públicas, por ejemplo.

Tolerancia. El Estado puede también mostrarse equidistante frente a determinada práctica o discurso inicialmente rechazable, y optar por no desalentarlo pero tampoco por promocionarlo.

Inclusión institucional. Este nivel constituiría el reverso de la disuasión estatal. Ante determinadas prácticas o discursos minoritarios, el Estado opta por implementar políticas de inclusión en instituciones y foros políticos, económicos y sociales, adoptando políticas de discriminación positiva o de cuota, por ejemplo, con el fin de reequilibrar la posición minoritaria o silenciada que los grupos sociales de referencia ocupan en sociedad.

Políticas de reconocimiento. En línea con las demandas del multiculturalismo (Taylor, 2003), este último nivel de relación con prácticas o discursos que, por ser minoritarios o entrar en conflicto con los valores mayoritarios, pueden ser prima facie ignorados o rechazados constituiría un paso más respecto de las políticas de inclusión, no limitado a la redistribución de bienes económicos y sociales, sino acogiendo una protección activa de las identidades culturales, ofreciendo a esas prácticas religiosas o culturales las mismas posibilidades de actuación y expresión social que a las hegemónicas u oficiales y protegiendo los símbolos culturales como referentes de la identidad grupal.

La decisión de si la reacción estatal ha de ser de mera tolerancia, de inclusión o reconocimiento, o bien de intolerancia, dependerá de la ponderación entre las razones de aceptación y de rechazo. Que la práctica social en cuestión sea, a su vez, intolerante, supondrá ya una importante razón de rechazo, que habrá de situar la balanza en el segmento de la intolerancia estatal: un principio básico de reciprocidad habría de llevarnos a renunciar a la tolerancia allí donde se responde con intolerancia (Forst, 2008: 77).

Pero será preciso determinar, a su vez, si la política de intolerancia ha de pasar por la represión o, como grado menos intenso, únicamente por la disuasión no coactiva. Cuando la práctica social intolerante se enmarque, como algunas formas del discurso de odio, en el ejercicio de un derecho fundamental, a dicha razón de rechazo se opondrá una poderosa razón de aceptación; no absoluta, desde luego -ningún derecho fundamental es absoluto-, pero sí de suficiente entidad como para que como regla general deba rechazarse el uso de la represión estatal. Así, prima facie la única razón de rechazo que justificaría llegar al uso de la represión sería un relevante grado de lesividad (McKinnon, 2008: 57): que la conducta expresiva genere un daño de suficiente entidad como para que el ejercicio del derecho fundamental deba ceder en favor del otro interés protegido, menoscabado por el discurso hostil.

Que no quepa apelar a la represión por estar ante un derecho fundamental no significa que el Estado deba mostrarse tolerante ante el discurso de odio, sino que, como decimos, puede intentar desalentar su práctica a través de otros mecanismos no sancionatorios. Desde luego, no existe un 
deber de promover el discurso del odio (con políticas de inclusión), pero tampoco existe una obligación de equidistancia y neutralidad (de tolerancia) frente a prácticas sociales que atentan contra los valores que permiten la convivencia. Desde esta perspectiva, la intolerancia tanto del Estado como de la sociedad civil puede legítimamente articularse a través de medios que silencien tanto el discurso hostil como otras prácticas discriminatorias, privándole de ayudas públicas, de foros de expresión, etc.

No pretendo manifestar con ello que, extramuros del ámbito estrictamente sancionador, el Estado tenga legitimidad para silenciar por otras vías discursos protegidos por la libre expresión. Ciertamente, también el ejercicio de la disuasión no coactiva, como forma menos intensa de intolerancia, debe estar sometida a los límites inherentes al derecho fundamental, y a garantías democráticas como la proporcionalidad o la igualdad (SUNSTEIN, 2007: 187 ss.). Así, de una parte, las restricciones a la libre expresión deberán graduarse en su intensidad en función del grado de protección que merezca el discurso. Por ejemplo, las medidas de disuasión deberán ser mínimas cuando estemos ante el ejercicio del derecho a la libre expresión por parte de un representante político en periodo electoral -núcleo del discurso político, como supuesto de máxima protección-, pudiendo ser mayores cuando el discurso tenga lugar en foros públicos más restringidos en los que concurran otros intereses protegidos, como la escuela o la universidad; asimismo, el grado de disuasión habrá de modularse igualmente en función del contenido del discurso: existirá mayor legitimidad de las políticas de disuasión frente a un discurso nítidamente racista que ante un discurso contrario a la inmigración irregular.

De otra parte, huelga decir que las políticas de disuasión no pueden utilizarse para silenciar una determinada doctrina religiosa o moral en favor de la mayoritaria, si la primera no resulta frontalmente hostil contra valores centrales de la democracia; esto es, si no hay razones legítimas de rechazo. Así, políticas como la prohibición del velo islámico o la exhibición del crucifijo en la escuela pública se muestran difícilmente compatibles con el principio de igualdad. En estos casos, considero que el Estado habría de mostrarse neutral -tolerante- ante las distintas tradiciones religiosas, y no privilegiar una en aras a proteger una pretendida identidad cultural mayoritaria frente a otras.

Decíamos antes que la inclusión constituía el reverso de la disuasión: un Estado democrático comprometido con los valores de la libertad y la igualdad no debe mostrarse neutral -tolerante- frente al discurso contrario a esos valores, siendo legítimo, por tanto, introducir regulaciones basadas en el contenido del discurso. Pero esa defensa activa de los valores democráticos puede obtener semejantes resultados tanto por la vía de la disuasión del discurso hostil como por la promoción de un discurso de resistencia frente a aquél y el refuerzo simbólico de los valores que ataca.

\section{El daño del discurso del odio}

Es un hecho indudable, en efecto, que el discurso de odio puede producir consecuencias perniciosas en la sociedad, tanto a la propia estabilidad social, que puede ver alterado su clima de paz social con la difusión de mensajes discriminatorios o intolerantes, como a las concretas personas que pueden considerarse destinatarias -y, en tal medida, víctimas- del rechazo y los mensajes denigratorios o intimidatorios.

Words that wound es el elocuente título del libro que en los primeros años noventa publicaron, compilando artículos anteriores, cuatro autores pertenecientes al movimiento critical race theory --Mari J. Matsuda, Charles R. Lawrence III, Richard Delgado y Kimberlè Williams Crenshaw-, con el declarado fin de denunciar la falta de atención de la doctrina y jurisprudencia imperante sobre la Primera Enmienda sobre los daños que producía el discurso racista. A lo largo de sus páginas se exponían las variadas consecuencias lesivas que el discurso racista generaba sobre sus destinatarios, desde secuelas psicológicas como estrés postraumático, psicosis, hipertensión o ataques de pánico, hasta la intimidación y el sentimiento de inseguridad física, pasando por la pérdida de autoestima y la reputación, un acentuado sentimiento de exclusión social o una pérdida de identidad y pertenencia.

Más recientemente, Jeremy Waldron publica The Harm in Hate Speech, en el que justifica la restricción legal (y penal) del discurso de odio sobre la base de los graves daños que causa, destacando entre ellos el menoscabo de la dignidad de las personas, entendido como la merma en la confianza en ser tratados como seres de pleno derecho, pero también de intereses como la sensación de seguridad o el "bien público de la inclusión", apelando a una suerte de daño ambiental basado en una contaminación de la atmósfera de respeto que debe imperar en una sociedad bien ordenada.

Lo que tienen en común las dos obras mencionadas es también lo que caracteriza a la discusión sobre los efectos negativos del discurso intolerante: la multiplicidad de propuestas y la variedad de daños que suelen atribuirse resulta indicativa de la dificultad de definir su lesividad. En buena medida, ello se debe al hecho de que bajo la genérica referencia al discurso de odio se engloben distintas conductas expresivas, susceptibles por ello se dar lugar a diversas consecuencias perniciosas; sin lugar a dudas, también la propia inmaterialidad de los objetos de agresión dificulta concretar el daño causado, obligando a acudir a símiles o metáforas para describir menoscabos de sentimientos, de expectativas normativas o de entornos comunicativos. Sin perjuicio de ello, no resultan desencaminadas las consideraciones de Hare y Weinsten -en su introducción a extreme Speech and Democracy, otra importante recopilación de trabajos sobre la materia- cuando destacan que las propuestas de restringir las expresiones hostiles suelen carecer "de bagaje teórico y se apoyan en una variable colección de justificaciones relativas a la paz y el orden social, la no discriminación, la ofensividad o la dignidad humana, a menudo sin afán de separar su análisis" (Hare y Weinstein, 2009: 7).

\section{El "efecto silenciador" como daño a la reputación comunicativa}

Entre el elenco de daños atribuidos al discurso del odio, destaca el que se ha venido caracterizando como "efecto silenciador". Desde esta concepción -defendida por señaladas voces del feminismo como Katherine MacKinnon o Caroline West, por representantes del critical race theory o por Owen Fiss, se afirma que los mensajes hostiles y discriminatorios, al minusvalorar la dignidad y negar el reconocimiento social de determinadas minorías, les impiden intervenir con plenitud en el debate público, pues sus palabras carecerán de toda influencia social al haber sido desautorizadas con la pérdida de reputación y consideración como iguales (Fiss, 1996).

West ha desarrollado esta tesis en un trabajo reciente. Parte de entender que el ejercicio de la libertad de expresión requiere el cumplimiento de tres condiciones: mínima distribución, mínima comprensión, y mínima consideración hacia su contenido. La mera posibilidad de proferir un mensaje a un auditorio no es suficiente para garantizar su ejercicio, sino que para ello será necesario un cierto grado de difusión del mensaje entre sus destinatarios, que el auditorio se halle en situación de entender su motivación y significado y que muestre cierta disposición a someterlo a reflexión 
crítica (West, 2012: 226 ss.). En una versión de mínimos, el derecho a la libre expresión -afirma West- no impone al Estado ni a los ciudadanos la obligación positiva de escuchar, comprender y mostrar consideración hacia los discursos ajenos, pero sí el deber negativo de no realizar conductas dirigidas a impedir tales condiciones mínimas del discurso, y el consiguiente deber del Estado de restringir tales conductas (West, 2012: 231).

Los mensajes racistas y denigratorios contra grupos culturales minoritarios impiden que el discurso de tales minorías pueda ser escuchado, comprendido y tenido en consideración por la opinión pública. Ello se debe no solo al clima intimidatorio que puede generar, y a la consiguiente disuasión basada en el temor a represalias, sino también a partir de una más sutil merma progresiva de la reputación de tales grupos como actores en la esfera pública, producida a través del asentamiento de prejuicios y estereotipos que dan lugar a una pérdida de autoestima y, por parte del auditorio, a que sus mensajes sean tergiversados o ignorados (West, 2012: 240-243; Matsuda, 1993: 25). Como consecuencia de esa merma en la "reputación comunicativa" -si así quiere denominarse- que genera el discurso de odio, las reivindicaciones de esos grupos minoritarios no conseguirán calar en la opinión pública y quedarán por ello fuera de la agenda política (Lawrence III, 1993: 69; Fiss: 1996).

\section{4. ¿Restringir la libertad de expresión para proteger la libertad de expresión?}

Sin lugar a dudas, la equitativa capacidad de intervenir y ejercer influencia en la esfera pública por parte de todos los ciudadanos y grupos sociales representativos constituye un elemento esencial de legitimidad de la democracia deliberativa, por lo que un Estado democrático debe aspirar a hacer efectiva esa participación equitativa y, por ello, a adoptar medidas dirigidas a fomentar la influencia y reputación comunicativa de los grupos más desaventajados. Desde esta perspectiva, no le falta razón a Todorov cuando asevera que "no basta con tener derecho a expresarse. Hay que tener la posibilidad de hacerlo. Si no se tiene, esa 'libertad' es una palabra vacía" (Todorov, 2012: 133).

No obstante, lo que no llega a justificarse por quienes denuncian ese efecto silenciador es por qué la estrategia a adoptar desde el poder público para amplificar las voces de los grupos minoritarios deba ser la restricción de la libre expresión de los intolerantes -ni, menos aún, que tal restricción deba adoptar la forma de la represión penal-. Ciertamente, acogiendo los gráficos términos de Owen Fiss, a fin de satisfacer esa demanda de las voces minoritarias será a veces necesario "repartir megáfonos" por el Estado "a aquellos cuyas voces de otra forma no serían oídas en la plaza pública" (Fiss, 1996: 14). Pero para ello existen otras posibilidades menos desproporcionadas que restringir la libre expresión política de los intolerantes. Sin ir más lejos, repartir megáfonos: esto es, políticas de inclusión de esos grupos desfavorecidos en el ámbito de la opinión pública, en lugar de políticas de represión de otros planteamientos políticos. Si el daño se produce sobre la repercusión comunicativa y sobre las posibilidades de interacción en la esfera de la opinión pública, es en ese ámbito donde debieran intentar buscarse remedios compensatorios (Post, 1991: 270).

\section{El ámbito de la opinión pública}

En toda aproximación, ya sociológica, ya política, al funcionamiento del sistema democrático, se destaca la importancia que para su desarrollo ostenta la existencia de una opinión pública vigorosa. En palabras de Habermas, el "espacio público-político" como ámbito donde se desarrolla la opinión pública, actúa a la vez como presupuesto y como garante de la democracia (Habermas, 1998: 439).

"Por espacio público -afirma- entendemos un ámbito de nuestra vida social, en el que se puede construir algo así como opinión pública. La entrada está fundamentalmente abierta a todos los ciudadanos. En cada conversación en la que los individuos privados se reúnen como público se constituye una porción de espacio público [...] Los ciudadanos se comportan como público, cuando se reúnen y conciertan libremente, sin presiones y con la garantía de poder manifestar y publicar libremente su opinión, sobre las oportunidades de actuar según intereses generales. En los casos de un público amplio, esta comunicación requiere medios precisos de transferencia e influencia: periódicos y revistas, radio y televisión son hoy tales medios del espacio público" (apud Boladeras, 2001: 53).

La esfera pública es, así, el ámbito social en el que la sociedad civil se interrelaciona comunicativamente (Sampedro, 2000: 53); en palabras de Dahlgreen, es un "espacio -de discurso, institucional o geográfico- donde la gente ejerce de ciudadano accediendo -de forma metafórica- al diálogo sobre las cuestiones que afectan a la comunidad, a la política en su sentido más amplio" (apud Sampedro, 2000: 30). Esa esfera de diálogo social adquiere, así, una relevancia esencial cuando se proyecta sobre el ámbito político, tanto en la influencia de la toma de decisiones como en la crítica a la actividad de los poderes públicos. "Cuando el ejercicio del dominio político se subordina efectivamente a la demanda pública democrática, logra el espacio público político una influencia institucional en el gobierno por la vía del cuerpo legislativo. El título 'opinión pública' tiene que ver con tareas de crítica y de control, que el público de los ciudadanos de un estado ejerce de manera informal (y también de manera formal en las elecciones periódicas) frente al dominio estatalmente organizado". En sociedades complejas, ese espacio público-político actuará, así, como "caja de resonancia para problemas que han de ser elaborados por el sistema político" (Habermas, 1998: 440 s.), erigiéndose como instancia de intermediación entre el poder político y los sectores privados e individuales que conforman la sociedad civil (Sampedro, 2000:20).

En sociedades multiculturales, la esfera de opinión pública estará conformada por distintas concepciones del bien común, por doctrinas enfrentadas acerca de los valores y normas que deben imperar en las relaciones intersubjetivas y de los límites al poder estatal; por ello, será inherente a su existencia cierto grado de conflicto y enfrentamiento dialéctico (Post, 2009: 133). Consustancial a la interacción comunicativa propia de esa esfera público-política es, de ese modo, la aspiración de cada una de las voces a ejercer influencia sobre la opinión de los demás participantes y, mediatamente, sobre la actividad y decisiones del poder político: "las opiniones públicas representan un potencial político de influencia que puede utilizarse para ejercer influencia sobre el comportamiento electoral de los ciudadanos o sobre la formación de la voluntad en los organismos parlamentarios, en los gobiernos y en los tribunales" (Habermas, 1998: 443).

Que la acción comunicativa de los actores se torne en acción política dependerá, así, de la capacidad de influir sobre las opiniones de ese auditorio (KNIGHT/JOHNSON, 1997: 280). Tal influencia dependerá, a su vez, del mayor o menor poder comunicativo que se ostente, basado en factores como el peso institucional o reputacional de los actores, las posibilidades de acceso a los medios de comunicación de masas, la auctoritas moral 0 la fama de que se goce, etc. En los términos de Sampedro, ese poder dependerá tanto del capital cultural, relativo a habilidades, competencias y conocimiento, como del capital simbólico de que se disponga, dependiendo éste del prestigio, reconocimiento y respeto adquirido (Sampedro, 2000: 23). 
En el espacio de la opinión pública, manifiesta Habermas,

se forma influencia y en él se lucha por ejercer influencia. En esa lucha no sólo entra en juego el influjo político ya adquirido y acumulado (por acreditados ocupantes de cargos públicos, por partidos políticos establecidos, o por grupos conocidos, como Greenpeace o Amnistía Internacional, etc.) sino también el prestigio de grupos de personas y también de expertos que han adquirido su influencia en espacios públicos más especializados (por ejemplo, la autoridad de eclesiásticos, la fama de literatos y artistas, la reputación de científicos, el renombre y relumbre de estrellas del deporte y del mundo del espectáculo, etc.) (Habermas, 1998: 443 s.).

Factores como la complejidad de las sociedades actuales, la profesionalización de los actores de la comunicación o la universalización de la comunicación (a través de internet), han dado lugar a la diversificación de roles, acentuándose la diferencia entre actores y espectadores, entre quienes intervienen activamente en esa aspiración de conformar la opinión pública y quienes, como auditorio y disponiendo de menor poder comunicativo, adoptan un papel más pasivo (Habermas, 1998: 455 ss.; Sunstein, 2007: 8). No obstante, es precisamente el auge de internet, con espacios como blogs de opinión o diversas redes sociales y con su infinita potencialidad de difusión y reproducción, lo que de algún modo ha permitido a cada ciudadano erigirse en actor de la comunicación política. La caja de madera donde se subía el orador en el parque ha sido sustituida -pero también multiplicada exponencialmente- por el tweet o el video de YouTube (Ash, 2016: 66). Como ejercicio de la deliberación pública, tan merecedor de protección deberá ser, en principio, la libre expresión del "bloguero" individual como la del periodista de un periódico de tirada nacional. Expresado en otros términos, los límites a la libertad de expresión no debieran ser distintos de los aplicables con carácter general en la esfera pública (Boix, 2016: 61 ss.). De cualquier modo, es indudable que internet presenta importantes particularidades en estas cuestiones, cuyo análisis merecería un estudio específico que, sin perjuicio de consideraciones puntuales, no será abordado aquí.

\section{Entre espontaneidad y regulación}

Como ha puesto de manifiesto Post, al debate público le es inherente una relación de tensión entre las necesidades de interacción crítica y de deliberación racional (Post, 1990: 643). De una parte, su función emancipadora y de transformación social exige que el debate público se libere de las normas y valores propios de cada una de las comunidades identitarias, incluida la hegemónica. A tal fin, será deseable también que los intervinientes en la esfera pública no actúen aislados en su entorno comunitario -constreñidos e influidos únicamente por los códigos morales y tradiciones que otorgan identidad al grupo- sino que se vean expuestos a argumentos y prácticas heterogéneas, a fin de enriquecer las respectivas concepciones del mundo, adquirir mayor disposición y tolerancia hacia mensajes divergentes y hacer más completa, en suma, la agenda de la deliberación pública. La diversidad cultural -y la diversidad de opiniones- puede constituir, así, un factor de riqueza y racionalidad en la deliberación pública, al obligar al ciudadano al enfrentarse críticamente a diferentes concepciones de lo correcto, y a sostenerlos o combatirlos con la fuerza de los argumentos (Post, 1990: 680).

Así lo ha venido resaltando también Cass Sunstein, considerando que uno de los requisitos necesarios para un sistema estable de deliberación pública es que los ciudadanos se vean enfrentados a contenidos y propuestas ajenas a su abanico de convicciones y que, por tanto, no habrían elegido voluntariamente (Sunstein, 2007: 5-6,30). Según las investigaciones desarrolladas por el autor norteamericano, fenómenos habituales en la esfera de comunicación pública como el filtrado selectivo de información-cada vez más habitual con internet y las nuevas tecnologías-y la tendencia a buscar la confirmación de las convicciones preexistentes, generan dinámicas de polarización en grupos ideológicos, lo que a su vez lleva a tales grupos a adoptar las posiciones más extremas y a la radicalización de sus previas convicciones (Sunstein, 2003: 111 ss.; Sunstein, 2007: 44 ss.). Frente a esa conformidad, y a fin de evitar la polarización, los ciudadanos han de salir de su zona de confort informativo e ideológico y ser sometidos a discursos diversos, y adversos. Es debido a ello que, parafraseando el título de una de sus obras, las sociedades necesitan el disenso: la disidencia, las culturas minoritarias o la incorrección política se revelan, así, como factores beneficiosos para la deliberación democrática (Sunstein, $2003: 104$ ss.). En suma, la restricción coactiva de discursos minoritarios, disidentes o incluso ofensivos para la moral dominante perjudica la propia calidad del debate. La imprescindible diversidad y el pluralismo demandan, en consecuencia, las mayores cotas posibles de libertad en el contenido del discurso público.

No obstante, la necesidad de mantener determinados estándares de racionalidad en los procesos de deliberación, así como la aspiración misma de conseguir esa diversidad de voces y propuestas, hará procedente sentar determinadas reglas del juego, dirigidas a posibilitar la ausencia de coacción por parte de los grupos mayoritarios y la cultura hegemónica, y un cierto grado de igualdad en las posibilidades de interacción en la esfera pública.

Esa referida "paradoja del discurso público" -entre espontaneidad y regulación- es sintetizada por Post en los siguientes términos:

la aspiración de que el discurso fluya libre de las restricciones que imponen los valores vigentes en la comunidad ly de alcanzar la condición necesaria de pura comunicación) se halla en tensión con la aspiración del proyecto social de que exista una deliberación racional y no coercitiva. La primera aspiración se sostiene en los valores de neutralidad, diversidad e individualismo; la segunda en el proyecto deliberativo de autogobierno democrático (Post, 1990: 642).

La aspiración normativa de racionalidad y de que el proceso dialógico opere en condiciones de igualdad, conlleva la necesidad de que el poder político, el Estado, intervenga en el ámbito de la esfera pública tanto con las herramientas del debate público como con los medios del Derecho, para, de una parte, asegurar que las reglas de juego propias de la deliberación publica son respetadas por los contendientes, y también para, en la medida de lo posible, reequilibrar los poderes de comunicación de los distintos actores, a fin de garantizar cierto grado de igualdad en la capacidad de intervención e influencia (Post, 1990: 642; Boladeras, 2001: 69). Siendo como es un bien esencial para la democracia, el Estado debe aspirar a garantizar las condiciones que permiten el florecimiento y desarrollo de la opinión pública, tanto la libertad de expresión -absteniéndose de restringir el contenido del discurso en función de sus planteamientos ideológicos- como las posibilidades de ejercicio equitativo de esa libre expresión regulando los procedimientos de deliberación y redistribuyendo el acceso a la esfera pública-.

En particular, dada la directa relación entre el poder comunicativo y la posibilidad de influenciar la agenda social, el principio de igualdad política, como baluarte esencial de la democracia deliberativa -y como precondición para una deliberación racional (Rawls, 2004: 53)-, exigirá una ponderada y cuidadosa intervención del poder estatal para amplificar las voces de aquellos grupos o comunidades situadas en la periferia de la esfera pública. Pero es importante resaltar que ello debe exigirse tanto por motivos de justicia y de legitimidad democrática como por motivos funcionales, en tanto 
en cuanto, como vimos, la heterogeneidad y diversidad de voces, propuestas y culturas redunda en la calidad de la deliberación y en el valor epistémico de las decisiones adoptadas.

Posibilitar el counter speech, el discurso de resistencia, de los grupos minoritarios frente al discurso racista y discriminatorio constituye, así, una tarea esencial del Estado en una democracia deliberativa. Afirma Sampedro que "la esfera central, si es de verdad pública, no admite mensajes contrarios a la convivencia sin una contrarréplica". El problema es que en muchas ocasiones las voces de grupos minoritarios quedan relegadas a "esferas periféricas" y no acceden a la esfera pública "central". Esa esfera pública central está "dominada por las instituciones más asentadas de la sociedad civil y que genera debates cohesionadores y formalizados, sobre la gestión del poder y los valores colectivos" (Sampedro, 2000: 42). La dificultad de intervenir en esa esfera pública lleva a grupos culturales e ideológicos minoritarios a refugiarse en esferas de deliberación periféricas, las cuales "sostienen comunidades y ofrecen incentivos a la participación contrarrestando las exclusiones de la esfera pública central". La consecuencia de ello será, tal como planteaba Sunstein, la polarización y progresiva radicalización de esas comunidades, por cuanto la identidad cultural que las aglutina conllevará la uniformidad de los debates y la corroboración de las propias cosmovisiones. Para evitar ese pernicioso efecto, será fundamental posibilitar la apertura de espacios de diálogo de esas minorías en una esfera pública común, lo que, a su vez, evitará su anquilosamiento dialéctico. En palabras del citado autor, "necesitamos abrir esa esfera pública central a las esferas periféricas, comprometidas con renovarla"; es decir, crear un "espacio común, que debiera nutrirse de otras esferas públicas más reducidas, si no quiere estancarse" (Sampedro, 2000: 42). En definitiva: "el espacio público es el espacio discursivo, físico o social 'donde la libertad puede aparecerse' (Benhabib). Pero esa libertad debe garantizarse en los dos planos que constituyen la sociedad civil: las instituciones y las actitudes ciudadanas para participar. Hay que reformar las primeras y cultivar las segundas, acercándonos a una democracia deliberativa" (Sampedro, 2000: 43).

\section{Regulación en la esfera pública: formas de intolerancia frente al discurso intolerante}

El equilibrio entre ambas aspiraciones -la de garantizar una interacción crítica fluida y libre y la de que la deliberación sea racional y equitativa-será siempre precario (Post, 1990: 682): un exceso de regulación de la esfera pública, restringiendo la libertad de expresión, puede socavar la primera aspiración, pero un déficit de regulación puede pervertir la expectativa de racionalidad y equidad de los procesos de deliberación pública. Ciertamente, la esfera de la opinión pública no es impermeable al contexto social, sino que, por el contrario, se conforma y desarrolla a partir de los prejuicios, convicciones y concepciones de lo bueno que rijan en cada sociedad (Post, 1991: 273). Por ello, el racismo o la xenofobia presente en la sociedad impregnarán necesariamente, con más o menos visibilidad, el tono y contenido de la deliberación pública, y podrán generar una menor atención, comprensión y consideración hacia el discurso reivindicativo de grupos minoritarios.

Con relación a ese efecto silenciador que autores como Fiss atribuyen a los mensajes hostiles, ya dijimos que sus planteamientos se desenvuelven en un marco de razonamiento especulativo y carente de corroboración empírica. Al igual que acontece con las actitudes sociales de discriminación, en las democracias estables occidentales ese efecto silenciador no provendrá tanto de discursos abiertamente racistas de grupos extremistas como de actitudes sociales más o menos difusas y más o menos arraigadas en los actores de la comunicación -medios y lobbies de comunicación, esencialmente- que son quienes, a la postre, determinan la agenda de debate público (Malik, 2009: 106). Es más, lo cierto es que ese fenómeno de anulación de las voces minoritarias -así como de la misma capacidad de influencia comunicativa- se deberá antes a factores estructurales de desigualdad económica y política, y a la consiguiente conformación de mayorías, que al goteo de discursos abiertamente hostiles (de páginas web radicales, de tweets racistas, de cánticos extremistas en campos de fútbol, etc.), tal como, de hecho, ha sido ya identificado en sociología desde los años setenta con la figura de la espiral de silencio (Sampedro, 2000: 100).

Lo que quiero poner de manifiesto es que, ya desde una perspectiva funcional, la pretensión de evitar ese efecto silenciador a través de la represión del discurso del odio está abocada al fracaso, resultando poco plausible que el Código penal esté en disposición de combatir o remediar un fenómeno social tan complejo. Sin lugar a dudas, el Estado puede y debe desempeñar un papel esencial tanto para combatir la discriminación como para garantizar un acceso equitativo al espacio de la opinión pública. Pero esa labor no debiera acometerse a través de la represión coactiva de quienes intervienen en la esfera de opinión pública, so pena de pervertir la propia finalidad del proceso de deliberación pública en una democracia, que no es sino evaluar la aceptabilidad racional de todas las opiniones políticas.

En este sentido, precisamente ese afán manifestado por Fiss o West de combatir la merma de la libre expresión (de unos) con la restricción coactiva de la libertad de expresión (de otros) se revela ya antagónico con los pilares de la democracia deliberativa. Como afirma Post,

el discurso público es el medio a través del que nuestra sociedad evalúa la aceptabilidad democrática de las ideas; excluir ciertas ideas como prima facie 'coercitivas' y, con ello, lesivas de la deliberación pública contradice precisamente esa finalidad. Por ello, el 'daño' a la deliberación pública no puede justificar restricciones al discurso racista (Post, 1991: p. 299).

Finalmente, no debe perderse de vista una consideración adicional: la represión coactiva de la libre expresión, máxime dada la vaguedad e indeterminación semántica que suele caracterizar a las leyes que sancionan el discurso del odio, puede venir a desalentar el propio discurso reivindicativo de las minorías culturales, quienes para evitar caer bajo las extensas y difusas redes penales se verán obligadas a moderar sus propios planteamientos reactivos contra los intolerantes (Malik, 2009: 105). Una protección robusta de la libre expresión protegerá también a las minorías de los abusos censores del Poder público (Greenawalt, 1995: 61; Weinstein, 2001: 150).

Ciertamente, cuando tal efecto silenciador de las minorías tenga lugar a través de la amenaza directa a miembros o representantes de grupos minoritarios -a través de la incitación a la violencia- sí será proporcionado acudir a la represión, precisamente porque la intimidación y la amenaza no forman parte de la esfera de opinión pública y sitúa a quienes la ejercen fuera del marco de la deliberación democrática (si se quiere expresar de otro modo: queda fuera de lo protegido por el derecho a la libre expresión). Sin embargo, y más allá de los supuestos de discursos directamente coactivos o amenazantes, o de incitación a la violencia, la represión punitiva del discurso intolerante resultará ilegítima, porque excluirá a priori y con medios coactivos lo que debiera ser fruto de la deliberación racional, y porque desalentará el ejercicio del discurso político, reduciendo la espontaneidad y libertad que debe presidir la deliberación sobre asuntos públicos.

Pero, como vimos, que no quepa apelar a la represión no significa que el Estado deba mostrarse tolerante ante el discurso de odio, sino que puede y debe intentar desalentar su práctica a través de otros mecanismos no sancionatorios. Desde luego, no existe un deber de promover el discurso 
del odio (con políticas de inclusión), pero tampoco existe una obligación de equidistancia y neutralidad (de tolerancia) frente a prácticas sociales que atentan contra los valores que permiten la convivencia. Desde esta perspectiva, la intolerancia del Estado puede legítimamente articularse a través de otras formas de rechazo al discurso de los intolerantes.

De una parte, el Estado está perfectamente legitimado para participar en la deliberación pública bajo las reglas de juego propias de la esfera pública, por lo que puede servirse de su poder expresivo para, interviniendo en el debate público como un actor más -si bien dotado de una considerable reputación institucional-, promover los valores democráticos y combatir la intolerancia de los grupos de odio (Post, 2012: 22; Ash, 2016: 84). Medios como la publicidad institucional, las campañas publicitarias, el patrocinio de determinadas organizaciones, etc., permitirán al Estado ejercer la necesaria "persuasión democrática" para defender los valores constitucionales, educar en los derechos, criticar los discursos de odio o, en su caso, ensalzar la reputación comunicativa de los grupos minoritarios (Brettschneider, 2013). Lejos de tener que mostrarse neutral, el Estado tiene un deber positivo de utilizar sus auctoritas comunicativa para convencer a la ciudadanía de las bondades de la deliberación pública y del rechazo al odio y la intolerancia; tiene la obligación de enfrentarse dialécticamente con el discurso del odio.

De otra parte, el Estado puede acudir a políticas económico-sociales para combatir ese efecto silenciador atribuido al discurso del odio fomentando la visibilidad y reputación comunicativa de los grupos minoritarios y promoviendo, en suma, un más equitativo acceso a la esfera pública. Esto, a su vez, puede llevarse a cabo a través de políticas de disuasión, silenciando en lo posible los mensajes de odio, o bien a través de políticas de inclusión, amplificando la voz de los grupos minoritarios. Las posibilidades de combatir el discurso intolerante por esos medios son muy variadas y de muy distinta naturaleza. Pueden ir desde la implantación de requisitos de financiación de partidos y asociaciones no gubernamentales hasta la inclusión de festivos de las culturas minoritarias, desde la introducción de cuotas en instituciones públicas hasta la introducción de asignaturas específicas en los programas educativos de los colegios, desde el fomento de la autorregulación de los medios de comunicación de masas (Ash, 2016: 70) o la introducción de códigos de conducta antidiscriminatorios en empresas, hasta la organización de eventos artísticos o culturales que promuevan la concienciación del pluralismo y la diversidad, pasando, cómo no, por medidas redistributivas que permitan el desarrollo económico de los miembros de grupos discriminados.

El juego combinado de tales políticas exige un delicado equilibrio para, de una parte, reducir materialmente las posibilidades de intervención de los mensajeros del odio en el debate público e, inversamente, ampliar la voz de los grupos marginados; de otra parte, para que desde el Estado se muestre un decidido apoyo hacia los grupos minoritarios y reforzar con ello, simbólicamente, la confianza de estos en su plena legitimidad como actores de la esfera de deliberación pública; pero al mismo tiempo, para evitar un desproporcionado desaliento del discurso sobre asuntos políticos, posibilitando con ello una razonable protección de la democracia deliberativa.

\section{Bibliografía}

Ash, T. G. (2016). Free Speech. London.

Boix Palop, A. (2016). La construcción de los límites a la libertad de expresión en las redes sociales. Revista de Estudios Políticos, 173.

Boladeras Cucurella, M. (2001). La opinión pública en Habermas. Anàlisi, 26.

Brettschneider, C. (2013). Value Democracy as the Basis for Viewpoint Neutrality. Northwestern University Law Review, 107.

Fiss, O. (1996). La ironía de la libertad de expresión. Barcelona: Gedisa.

Forst, R. (2008). Toleration, justice and reason. En McKinnon y Castiglione, The culture of toleration in diverse societies. Manchester.

Greenawalt, K. (1996). Fighting Words. Individuals, Communities, and Liberties of Speech. Princeton.

Habermas, J. (1998) Facticidad y validez. Madrid.

Hare, I. y Weinstein, J. (2009). Extreme Speech and Democracy. Oxford.

Knight, J. y Johnson, J. (1997). What Sort of Equality Does Deliberative Democracy Require? En Bohman y Rehg, Deliberative Democracy, Essays on Reasons and Politics. Cambridge.

Matsuda, M. J., Lawrence III, C. R., Delgado, R., Williams Crenshaw, K. (1993). Words that Wound. Critical Race Theory, Assaultive Speech and the First Amendement. Boulder.

Malik, M. (2009) Extreme Speech and Liberalism. En Hare y Weinstein, Extreme Speech and Democracy. Oxford.

McKinnon, C. (2006). Toleration. A critical introduction. Oxon.

Post, R. (1990). The Constitutional Concept of Public Discourse: Outrageous Opinion, Democratic Deliberation, and Hustler Magazine v. Falwell. Harvard Law Review, 103. 
Post, R. (1991). Racist Speech, Democracy, and the First Amendment. William \& Mary Law Review, 32.

Post, R. (2009). Hate Speech. En Hare y Weinstein, Extreme Speech and Democracy. Oxford.

Post, R. (2012). Interview with Robert Post. En Herz y Molnar, The Content and Context of Hate Speech. Rethinking Regulation and Responses.

Rawls, J. (2004). El liberalismo político. Barcelona.

Sampedro Blanco, V. (2000). Opinión pública y democracia deliberativa. Medios, sondeos y urnas. Madrid.

Sunstein, C. (1993). Democracy and the Problem of Free Speech. New York.

Sunstein, C. (2003). Why Societies Need Dissent. Cambridge.

Sunstein, C. (2007). Republic.com 2.0. Princeton.

Taylor, C. (2003). La política del reconocimiento. En VV.AA., Multiculturalismo y la política del reconocimiento. México.

Todorov, T. (2012). Los enemigos íntimos de la democracia. Barcelona.

Waldron, J. (2012). The Harm in Hate Speech. Harvard.

Walzer, M. (1997). On toleration. New Haven.

Weinstein, J. (2001). Hate Speech, Viewpoint Neutrality and the American Concept of Democracy. En Hensley, The Boundaries of Freedom of Expression \& Order in American Democracy. Kent.

West, C. (2012). Words That Silence? Freedom of Expression and Racist Hate Speech. En Maitra y McGowan, Speech and Harm. Oxford.

\section{Cómo citar este artículo en bibliografías - How to cite this article in bibliographies / references:}

ALCÁCER-GUIRAO, R. (2018): "Discurso intolerante y esfera pública". En Revista de la Asociación Española de Investigación de la Comunicación, vol. 5, número 10, pp. 39-46. 